of buildings to withstand earthquakes, of which the author has had unique experience. This subject is discussed and illustrated by solutions to problems in which prescribed buildings are considered as a whole and as a structure composed of interconnected beams, columns and trusses. Here, too, the important question of foundations is dealt with, and in the same group may be mentioned the vibratory effects of traffic on roads.

The range of examples introduced is much too wide to be particularly classified, but it may be mentioned that they are representative of civil, mechanical, aeronautical, structural and marine engineering, and afford trustworthy guidance for most cases met with in practice.

\title{
ROCK-PAINTINGS IN SOUTH AFRICA
}

\section{More Rock-Paintings in South Africa}

From the Coastal Belt between Albany and Piquetberg. Mainly copied by Joyce and Mollie van der Riet. With Notes by the same and an Introduction and Explanatory Remarks by Dorothea F. Bleek. Pp. $\mathrm{xx}+28+28$ plates. (London: Methuen and Co., Ltd., 1940.) 42s. net.

THIS volume, which has only thirteen pages of text, one map and twenty-eight plates with an explanatory page by Miss Bleek for each sheet of plates, describes a chosen number of rock paintings in the district of Grahamstown, halfway between Cape Town and Durban. They are some of the 145 examples copied by Miss van der Riet, Mrs. Ginn, Miss Sheila Fort and Miss Bright. There are also three plates of rather mediocre rock engravings, interesting because they show the extension southwards of this type of art. Some photographs of the originals are included.

On the whole, the art of the panels reproduced is not of a very high level, although the elephant shaded in reddish-brown (pl. 16-17) is very fine and so are the clothed and equipped archers (pl. 26), recalling some of the finest panels of Natal.

Among the most interesting subjects reproduced, all purely Bushman and previous to the arrival of other races, are the line of galloping springboks (pls. 15, 17, 19, 21A) in red, in the style I call 'spidery'; the battle between two tribes of Bushmen (pl. $5 A$ ) in red ; the group of kneeling archers also in red drawing their bows (pl. $6 B$ ); the flying birds and circles of seated men painted in red (pl. 23) ; the little elephants grouped in a footprint of that animal (?) (pl. 27) also in red.

We must mention certain animals with their outline drawn in red and not filled in with colour, such as those in pl. $8 A$ and $B:$ one of these is an antelope, not an ox, with its horn (pl. $8 A$ ), seen full face, an example of twisted perspective rare in South African art.
There are very few big two-colour paintings of elands, and they are poor (pls. 1 and 28); the better two-colour paintings, which are rather good, are of antelopes (pl. 5B) and quagga (?) (pl. 10B). There are a few plants (?) (pls. $14 A$ and 24); a rainbow (?) (pl. 7); an apron (?) (pl. 7) ; a skin water bottle (?) with its cords (pl. 19) near a man who seems to be climbing skywards with a rope; the spots near him suggest a rain-making rite.

A good many superpositions of the paintings are mentioned, only some of which are shown (pl. $5 A$ and $B$ ); brownish-red on faded red (pl. 23) ; three levels, yellow, red, then black (pl. 26) ; the black figures are obviously the latest in pls. $7,9,20,25,26$; there are several paintings of baboons. A fine white and black ostrich reminds us of the celebrated ones published by Stow with the hunter disguised as an ostrich (pl. 2).

It is a pity this volume does not contain the whole block of paintings copied, even if only as small line drawings, for the chief interest in a regional investigation lies in an exhaustive study of the superpositions and styles which it exhibits. For example, stencilled feet and hands are mentioned, but there is no reproduction of them. It is said they are sometimes older and sometimes more recent than the figures; I can only say that at Riversdale, as at Wilton, where I saw them, they were far older than the figures. No late panels are given showing sheep, oxen, horses, etc. ; such plates would have been valuable, making the book more complete. I have seen, for example, at Wilton, a big group of Hottentot white sheep with fat tails.

Still we thank Miss Bleek for having, so far as she could, enriched this publication, which completes her previous magnificent volume, and encourage her to pursue her fascinating study. She has pointed out in the text, with that authority which is her right, the differences in the artistic character of the various South African regions, differences which I need not enumerate.

H. BreUIL. 